\title{
Preparation of Biodiesel From Karanja (Pongamia Pinnata) Oil
}

\author{
M. Rakib Uddin ${ }^{1 *}$, Kaniz Ferdous ${ }^{1}$, Sukanta Kumar Mondal ${ }^{1}$, Maksudur R. Khan ${ }^{1,2}$, M. A. Islam ${ }^{1}$ \\ ${ }^{1}$ Department of Chemical Engineering and Polymer Science, Shahjalal University of Science and Technology \\ (SUST), Sylhet 3114, Bangladesh. \\ ${ }^{2}$ Faculty of Chemical and Natural Resources Engineering, Universiti Malaysia Pahang, 26300 Gambang, Kuantan, \\ Pahang, Malaysia.
}

\begin{abstract}
:
Biodiesel is a biodegradable, sustainable and clean energy has worldwide attracted renewed and growing interest in topical years, chiefly due to development in biodiesel fuel and ecological pressures which include climatic changes. In this paper, karanja (pongamia pinnata) seed has been studied as a potential source for biodiesel preparation. Karanja oil is extracted from the seed by different methods. Oil properties have been measured by standard methods. Acid catalyzed transesterification, acid catalyzed two-step method and three-step method have been studied for biodiesel preparation from karanja oil. In the three-step method, the first step is saponification followed by acidification to produce free fatty acid (FFA) and finally esterification of FFA to produce biodiesel. In saponification, acidification and esterification reaction, the reaction parameters were optimized. Silica gel was used in both transesterification and esterification to adsorb water, produced in the reaction hence increase the reaction rate. Properties of biodiesel such as specific gravity, FFA, Viscosity, saponification value, iodine value, cloud point, pour point, flash point, cetane index, calorific value etc are measured and compared to conventional diesel fuel and standard biodiesel.
\end{abstract}

Keywords: Biodiesel; Transesterification; Saponification; Esterification; Free Fatty Acid.

\section{Introduction}

Increasing the consumption and price hike of petroleum fuel day to day is really problems for developing countries those are dependent on foreign suppliers and pay huge amount of import bill. During the last decade, the use of alternative fuel in diesel engines has received renewed attention. The uncertainty of petroleum-based fuel availability has created a need for alternative fuels [1]. Hence research on biodiesel as an alternative of diesel is in progress. Biodiesel is renewable fuel, it has simple technology of production, low handling hazards, emits low pollutants, and can be used in engine without substantial modifications [2]. The main source of biodiesel i.e. oil producing plant, can grow easily in wide range of geographic locations and flexible climatic conditions. Among the edible and non-edible vegetable oils, the non-edible oils such as jatropha, karanja, putranjiva etc are economical as biodiesel for its less consumption in domestic purposes. It is widely agreed that biodiesel decreases the emissions of hydrocarbons (HC), carbon monoxide (CO), particulate matter (PM) and sulphur dioxide (SO2). It is also said to be carbon neutral as it contributes no net carbon dioxide to the atmosphere [3]. Other countries have seriously considered the massive use of bioenergy in the future. China, Germany, Austria and Sweden have set goals of utilizing $10-15 \%$ of their internal primary energy supply through bioenergy up to the year 2020, where Vietnam has set a target of using bioenergy i.e. $37.8 \%$ of the total energy consumption [4]. Literature shows already that many researches are done on non-edible vegetable oils such as jatropha, mahua, karanja, neem etc. and edible vegetable oils separately to study the performance and emission characteristics of these in diesel engine. Jatropha, karanja and putranjiva plants are abundantly available in tropical and subtropical regions in Bangladesh. The seeds from these plants go waste annually which can be utilize for biodiesel production and hence may solve partly fuel crisis problem.

Four major techniques (dilution, microemulsion, pyrolysis, and transesterification modification techniques) are used for biodiesel production, among them transesterification process has been widely used to reduce the high viscosity of the oil. Transesterification reaction can be catalyzed by both homogeneous (alkalis and acids) and heterogeneous catalysts. The most commonly used alkali catalysts are $\mathrm{NaOH}, \mathrm{CH} 3 \mathrm{ONa}$, and $\mathrm{KOH}$ [5]. It has been found that the alkalinecatalyzed transesterification process is not suitable to produce biodiesel from unrefined oils [6] where the FFA content is higher. In order to prevent saponification during the reaction, FFA and water content of the feed must be below 0.5 wt.\% and 0.05 wt. $\%$ respectively. Because of these limitations, only pure vegetable oil feeds are appropriate for alkali-catalyzed transesterification without extensive pre-treatment [7]. Homogeneous acid catalyzed reaction is about 4000 times slower than the homogeneous base-catalyzed reaction and hence is not popular for industrial production of biodiesel.

A two-step process has been used for biodiesel production from oil, where in the first step acidcatalyzed esterification is conducted to convert the FFA to fatty acid methyl ester (FAME) followed by the acid catalyzed transesterification to convert the triglyceride (TG) to FAME [8]. Another approach was reported for 
biodiesel production from non-edible oil, where FFA was produced from oil by saponification-acidification reaction and FAME is produced by acid catalyzed esterification reaction [9]. In the present paper biodiesel is prepared from karanja oil by different methods. The difficulties of each process are discussed and the biodiesel properties are measured and compared with standard diesel and biodiesel property.

\section{Materials and Methods}

\subsection{Chemicals}

Methanol (99-100\%), ethanol (99-100\%), sodiumhydroxide pellets $(96 \%)$, potassium hydroxide pellets $(>84 \%)$, phenolphthalein $(\mathrm{pH} 8.2-9.8)$, starch, acetone (99\%), n-Hexane(96\%), hydrochloric $\operatorname{acid}(37 \%)$, isopropanol, iodine, sodium iodide, glacial acetic acid, bromine, carbon tetrachloride etc. were purchased from Merck. All the chemicals used were analytical reagent grade.

\subsection{Extraction of oil}

Different methods were used to extract oil from the seed [10]. For mechanical press, a vertical, manual operated, cylindrical (4.3 cm ID) mechanical press with spiral screw was used. A Soxhlet Extraction unit was used for oil extraction where hexane was refluxed for $6 \mathrm{~h}$ for a given amount of karnel mass.

\subsection{Biodiesel preparation from oil}

\subsubsection{Acid catalyzed transesterification}

Biodiesel from non-edible oil was prepared by acid catalyzed transesterification reaction [11]. The reaction was carried out at $70{ }^{\circ} \mathrm{C}$ and atmospheric pressure under reflux for 18 hours with vigorous stirring. Typically 50 gm of oil sample were placed in a three-necked $250 \mathrm{~mL}$ round bottom flask equipped with a reflux condenser. The flask was placed in an electric heater with a temperature controller and magnetic stirrer. Concentrated sulfuric acid (2 wt \% of oil) was mixed in required amount of methanol. Methanol was used 9:1 molar ratio to oil. The methanesulfonic acid solution was transferred into the reaction flask. After 18 hours, the contents were cooled to room temperature. After the reaction, the biodiesel was purified by hot water wash. For this purpose hot water and biodiesel mixed together in separatory funnel and shaking. Then allow stand for phase separation. Water is heavier than biodiesel and absorbs the excess alcohol, catalyst and impurities. After washing and settling, the water and the impurities in the water are drained from the bottom of the separatory funnel. Several wash cycle are generally needed. The first washed water drained from funnel will be milky and the final washed water drained off will be clear. The washed biodiesel was then dried at $100{ }^{0} \mathrm{C}$ under vacuum.

\subsubsection{Two step method}

A two-step acid-catalyzed methanolysis of higher FFA containing oil was adopted for the conversion of FFA and TG to FAME [8]. In brief, in the first step esterification was carried out at $60{ }^{\circ} \mathrm{C}$ and atmospheric pressure with a molar ratio of methanol/oil as 5/1. Sulfuric acid ( $2 \mathrm{wt} \%$ of oil) was used as catalyst and reaction was carried out for $2 \mathrm{~h}$. After $2 \mathrm{~h}$ the contents were cooled to room temperature and reaction product was washed with hot water in a seperatory funnel until clear water found and dried under vacuum at $100{ }^{\circ} \mathrm{C}$ for $20 \mathrm{~min}$. The product of acid catalyzed esterification reaction was subjected to acid catalyzed transesterification reaction. In this reaction $2 \mathrm{wt} \%$ of sulfuric acid to oil was mixed with required amount of methanol. Methanol was used 9:1 molar ratio of oil. The methanolysis was performed under vigorous stirring at 100 0C. After $6 \mathrm{~h}$ the contents were cooled to room temperature and reaction product was washed with hot water until clear water found. The organic phase was collected and dried under vacuum at 100 0C for $30 \mathrm{~min}$.

\subsubsection{Three-step method}

In this method the raw oil was saponified, acidified and esterified sequentially [10]. Saponification was carried out by different stoichiometric amount of aqueous calcium oxide solution at $100{ }^{\circ} \mathrm{C}$ for different time. The reaction time and molar ratio of oil to calcium oxide were optimized. After saponification, the soap solution were treated with different stoichiometric amount of concentrated hydrochloric acid at a temperature of 60 $70{ }^{0} \mathrm{C}$ with vigorous stirring. After dissolving the soap, the FFA contents were separated in separatory funnel. The FFA content was determined by titrimetric method. Esterification of FFA was carried out as similar the first step of the two-step method. In esterification reaction silica gel was used to adsorb water produced in esterification reaction, hence increase the reaction rate. The molar ratio of FFA to methanol, catalyst concentration and reaction temperature were optimized. The biodiesel was washed by hot water and dried under vacuum at $100{ }^{\circ} \mathrm{C}$ temperature.

\subsection{Analytical Methods for Oil and Biodiesel}

FFA in the oil and biodiesel samples was analyzed by the method described in AOCS Aa 6-38 [12]. To determine FFA of sample, 4-5 gm of samples were dispersed in isopropanol $(75 \mathrm{~mL})$ and hexane $(15 \mathrm{~mL})$ followed by titration against $0.25 \mathrm{~N} \mathrm{NaOH}$. Saponification value (SV) was determined by the method described by Jeffery et al [13]. To determine SV $1 \mathrm{gm}$ sample was taken with $25 \mathrm{~mL}$ alcoholic $\mathrm{KOH}$, heated for one hour in a steam bath with occasional shaking and titrated the excess $\mathrm{KOH}$ with the $0.5 \mathrm{M}$ hydrochloric acid. The iodine value (IV) were determined by titrating $0.01 \mathrm{~N}$ sodium thiosulfate to the mixture of tested fuel and chemical reagents until the disappearance of the blue color based on the analysis 
methods of American Oil Chemist's Society. IV was calculated by the following Eq. 1:

Iodine value $=(B-S) \times N \times 0.001269 / W$

Where, $S$ and $B$ are the amounts (in unit of $\mathrm{mL}$ ) of sodium thiosulfate titrated for the tested sample and blank sample, respectively; $N$ is the molar concentration (in unit of mol/L) of sodium thiosulfate; and $W$ is the weight (in unit of $\mathrm{g}$ ) of the tested sample. Cetane index (CI) was calculated by following equation [14]:

$$
\mathrm{CI}=\mathrm{a}+\frac{\mathrm{b}}{\mathrm{x}}+\mathrm{cy}
$$

Where, $\mathrm{x}$ is the saponification value, $\mathrm{y}$ is iodine value a, b, c are constants. Here, a, b, c was calculated by using the above equation for palm, peanut and soybean oil fatty acid methyl esters respectively.

Physical properties such as moisture content and density of the oil were determined by following ASTM D 1744 (Karl fisher method), ASTM D 1480/81 and ASTM D 240 respectively. Viscosity, flash point, pour point and cloud point were determined by standards ASTM D445, ASTM D 93 (Pensky-Martens Flashpoint Apparatus, Lazer Scientific Inc, Germany), ASTM D 2500 and ASTM D 97 respectively.

\section{Results and Discussion}

\subsection{Extraction and Characterization of Karanja Oil}

The oil was extracted from Karanja seed by different methods and the oil content in the seed were 10.8 (wt/wt) \% and $23.4(\mathrm{wt} / \mathrm{wt}) \%$ found by press method and sox let extraction method respectively.

The properties of extracted karanja oil was measured by standard method and presented in Table 1.

Table 1: Properties of karanja oil.

\begin{tabular}{lc}
\hline Property & Value \\
\hline Specific gravity, at $25^{\circ} \mathrm{C}$ & 0.97 \\
Kinematic viscosity $(\mathrm{mm} 2 / \mathrm{s})$, at $40^{\circ} \mathrm{C}$ & 64 \\
FFA content $(\%)$ & 12.1 \\
Moisture content $(\%)$ & 0.08 \\
Saponification value $(\mathrm{mg}$ of $\mathrm{KOH} / \mathrm{gm}$ & 193.5 \\
of oil) & \\
Cetane Index & 54.5 \\
Iodine value $\left(\mathrm{g} \mathrm{I}_{2} / 100 \mathrm{~g}\right.$ oil $)$ & 83.8 \\
Odor & Mild flavor \\
Color & Dark \\
& brown \\
${ }^{*}$ Molecular Weight $(\mathrm{gm} / \mathrm{mol})$ & 889.1 \\
\hline
\end{tabular}

*Molecular weight was determined from composition of the oil.

\subsection{Preparation of Biodiesel 3.2.1. Biodiesel Preparation by Acid Catalyzed Transesterification reaction}

The properties of biodiesel produced by acid catalyzed transesterification reaction are presented in Table 2 . Viscosity and FFA content of the transesterification reaction product is higher than the biodiesel standard due to its higher FFA content in the raw oil. The acid catalyzed single step process is time consuming and even after $18 \mathrm{~h}$ the viscosity of the biodiesel is not comparable with the standard biodiesel viscosity.

\subsubsection{Biodiesel Preparation by Two-step Methods}

Biodiesel was prepared from karanja oil by two-step method. In the first step (acid catalysed esterification) FFA was reduced with time. The FFA reduction was presented in Figure 1. From the figure it was observed that after $2 \mathrm{~h}$ the FFA remain less than $2 \%$.

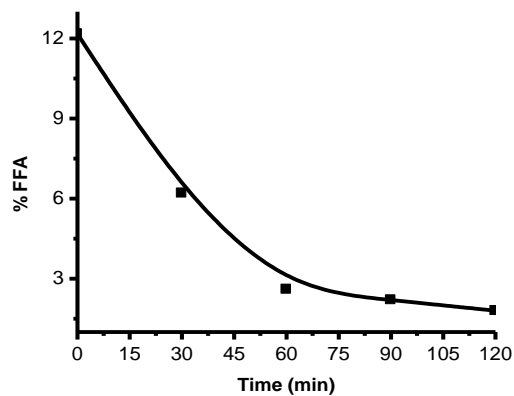

Fig. 1: Reduction of FFA in acid catalyzed esterification reaction [Reaction temperature $=60{ }^{\circ} \mathrm{C}$, Methanol to oil molar ratio 5:1, and catalyst concentration $2 \mathrm{wt} \%$ of oil under reflux with vigorous stirring].

After the esterification reaction the product was subjected to acid catalyzed transesterification reaction. Acid catalyzed transesterification requires $6 \mathrm{~h}$ instead of $2 \mathrm{~h}$ reported by Zullaikh et al. The properties of biodiesel produced by two-step methods are represented in Table 2. The viscosity and FFA content of produced biodiesel by tow-step method was slightly higher than biodiesel standard but this process is also time consuming.

Table 2: Properties of biodiesel produced by acid catalyzed transesterification and two-step method

\begin{tabular}{lcc}
\hline \multicolumn{1}{c}{ Property } & $\begin{array}{c}\text { Biodiesel } \\
\text { produced by Acid } \\
\text { catalyzed } \\
\text { transesterification } \\
\text { method }\end{array}$ & $\begin{array}{c}\text { Biodiesel } \\
\text { produced by } \\
\text { Two-step } \\
\text { method }\end{array}$ \\
\hline $\begin{array}{l}\text { Color } \\
\text { Viscosity } \\
\left(\mathrm{mm}^{2} / \mathrm{s}\right) \text { at } 40{ }^{0} \mathrm{C}\end{array}$ & Radish-black & Radish-black \\
Saponification & 12.8 & 6.7 \\
value (mg & & \\
KOH/gm oil) & 39.20 & 155.5 \\
$\begin{array}{l}\text { FFA (wt\%) } \\
\text { Specific gravity }\end{array}$ & 2.2 & 1.5 \\
\hline & 0.93 & 0.9 \\
\hline
\end{tabular}




\subsubsection{Three-step method for biodiesel Preparation}

Oil was converted to FFA by saponification of oil followed by acidification mentioned above. The results are represented in Figure 2. From Figure 2, it can be seen that the optimum molar ratio of oil to calcium oxide was 1:2 and reaction time was only $1 \mathrm{~h}$. Further increase in the molar ratio of oil to calcium oxide and reaction time, the conversion of oil to soap remain unchanged.

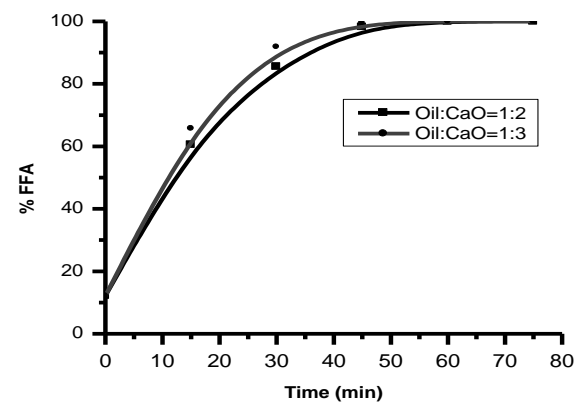

Fig. 2: Preparation of FFA from karanja oil through saponification and acidification by different stoichiometric molar ratio of calcium oxide to oil in aqueous solution $\left[\right.$ Reaction temperature $=100{ }^{\circ} \mathrm{C}$ under reflux with vigorous stirring].

FFA obtained from oil was subjected to esterification reaction to convert biodiesel. The reaction was carried out with different FFA/methanol molar ratio in presence of acid catalyst $\left(\mathrm{H}_{2} \mathrm{SO}_{4}\right)$. Effect of FFA/Methanol molar ratio was investigated at $60{ }^{\circ} \mathrm{C}$ and $5 \mathrm{wt} \%$ of catalyst. The maximum conversion of FFA to methyl ester was found for FFA/ methanol molar ratio of 1:9 after $2 \mathrm{~h}$. At optimum molar ratio of FFA to methanol the FFA conversion was $94.2 \%$ and $5.8 \mathrm{wt} \%$ FFA remain in the biodiesel. After prolonged reaction time could not reduced the FFA to desired level. In order to eliminate this problem, the esterification reaction was carried out in presence of silica gel. It was found that the presence of silica gel increased the rate of reaction and the final FFA conversion was $99.05 \%$ by using 5 gm silica gel in 50 gm FFA. Further increase in molar ratio of alcohol to FFA and silica gel the conversion of FFA and viscosity remain unchanged. The results are presented in Figure 3.

Effect of Catalyst Concentration was studied at FFA/methanol molar ratio of $1: 9$ at $60{ }^{\circ} \mathrm{C}$ in presence of silica gel and the results are presented in Fig. 4.

Fig 4 shows that $99.05 \%$ conversion of FFA can be achieved by $5 \mathrm{wt} \%$ catalyst $\left(\mathrm{H}_{2} \mathrm{SO}_{4}\right)$ concentration. Further increase in catalyst concentration has no effect on FFA conversion.

Effect of temperature on esterification reaction was studied. The results are presented in Fig 5. It can be seen that the temperature has a significant effect on the conversion of esterification reaction. As the temperature increased, the conversion was also increased. Figure 5 shows that $99.05 \%$ conversion of FFA can be achieved at $60{ }^{0} \mathrm{C}$. Further increase in temperature has no impact on FFA conversion.
3.4 Optimum parameters for three-step methods The optimum reaction parameters for three-step process are represented in Table 3.

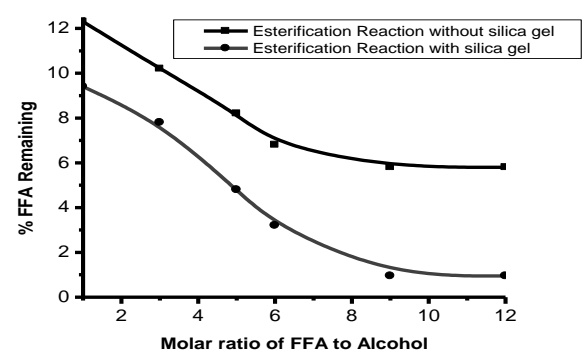

Fig. 3 : Conversion of FFA to biodiesel at different FFA/ methanol molar ratio in absence and presence of silica gel [Reaction temperature $=60{ }^{0} \mathrm{C}$, Catalyst $\left(\mathrm{H}_{2} \mathrm{SO}_{4}\right)$ concentration 5.0 wt $\%$ of FFA and Reaction time $2 \mathrm{~h}$ under reflux with vigorous stirring].

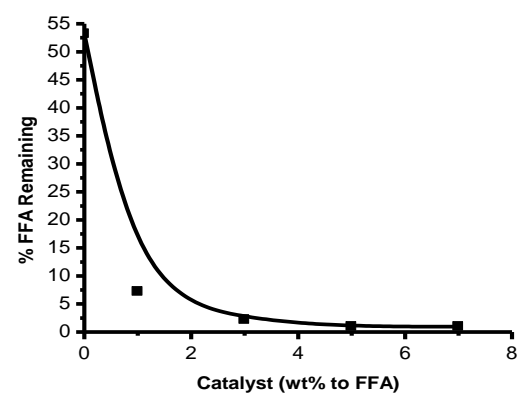

Fig. 4: Effect of catalyst $\left(\mathrm{H}_{2} \mathrm{SO}_{4}\right)$ concentration on esterification reaction [Reaction temperature $=60{ }^{0} \mathrm{C}$, FFA / methanol ratio 1:9 and Reaction time $2 \mathrm{~h}$ under reflux with vigorous stirring ].

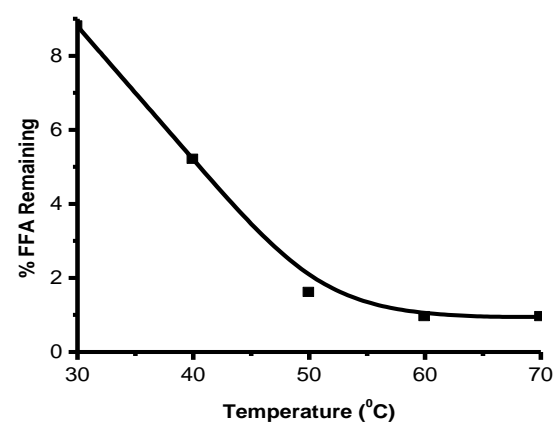

Fig. 5: Effect of Temperature on esterification reaction [Catalyst concentration $5 \mathrm{wt} \%$ of FFA, FFA / methanol molar ratio 1:9, Reaction time $2 \mathrm{~h}$ under reflux with vigorous stirring].

\subsection{Properties of biodiesel produced by three-step method}

Biodiesel was prepared from karanja oil at optimum reaction condition and the properties of produced biodiesel such as viscosity, density, flash point, cloud point, pour point, calorific value, FFA content, copper strip corrosion etc. are measured and shown in Table 4. Physical properties of biodiesel were compared with standard biodiesel properties. All of the measured values were in the range of standard biodiesel values. 
Table 3: Optimum reaction parameters for three-step process

\begin{tabular}{lll}
\hline Step & Parameters & Value \\
\hline Saponification & $\begin{array}{l}\text { Molar ratio of oil to } \\
\text { CaO }\end{array}$ & $1: 2$ \\
& $\begin{array}{l}\text { Reaction Time } \\
\text { Acidification }\end{array}$ & $1.0 \mathrm{~h}$ \\
& $\begin{array}{l}\text { Molar ratio of Soap } \\
\text { to HCl }\end{array}$ & $1: 1.5$ \\
Esterification & $\begin{array}{l}\text { Molar ratio of FFA } \\
\text { to Methanol }\end{array}$ & $1: 9$ \\
& $\begin{array}{l}\text { Reaction } \\
\text { Temperature }\end{array}$ & $60{ }^{0} \mathrm{C}$ \\
& $\begin{array}{l}\text { Catalyst }\left(\mathrm{H}_{2} \mathrm{SO}_{4}\right) \\
\text { concentration }\end{array}$ & $5 \mathrm{wt} \%$ to \\
& FFA \\
& Reaction time & $2.0 \mathrm{~h}$ \\
\hline
\end{tabular}

\section{Conclusion}

Biodiesel has been prepared from karanja oil by acid catalyzed transesterification reaction, two-step method and three-step methods. Among these methods transesterification is best because it requires fewer amounts of equipment and investment. But base catalyzed transesterification is not used for the preparation of biodiesel from karanja oil because of its high FFA content. Acid catalyzed transesterification reaction was done for the preparation of biodiesel. The viscosity of oil reduces from $64 \mathrm{~mm}^{2} / \mathrm{s}$ to $12.8 \mathrm{~mm}^{2} / \mathrm{s}$ and FFA reduces from $12.1 \%$ to $2.2 \%$ after $18 \mathrm{~h}$ of reaction. The product was not used as biodiesel because of its higher viscosity and FFA content and the process was time consuming. Acid catalyzed two-step method was performed for the preparation of biodiesel. In acid catalyzed esterification and transesterification the viscosity oil reduces from $64 \mathrm{~mm}^{2} / \mathrm{s}$ to $6.7 \mathrm{~mm}^{2} / \mathrm{s}$ and FFA of the oil reduces from $12.1 \%$ to $2.2 \%$. The value of FFA and viscosity are slightly higher than biodiesel standard and the reaction was time consuming.

Three-step method, where FFA was produced by saponification and acidification of oil and thereafter biodiesel was produced by esterification of FFA. The reaction parameters such as temperature, molar ratio of FFA to alcohol and catalyst concentration were optimized. Hence three-step method can be used for biodiesel production from karanja oil. Biodiesel properties was measured by standard methods and compared with the standard biodiesel properties. The copper strip corrosion test showed non corrosive nature of the biodiesel, it can be safely used in the diesel engine.

\section{Acknowledgement}

The authors express their deep gratitude to the University Grant Commission (UGC) for financial support to conduct this research.

\section{References}

[1] Verhelst S. and Sierens R. (2001), Aspects concerning the Optimization of a Hydrogen Fueled Engine, Int. J. Hydrogen Energy, 26: 981-985.

[2] Demirbas A. (2007), Progress and recent trends in biofuels, Progress in energy and combustion science, 33: 1-18.

[3] Lang X., Dalai A.K., Bakhshi N.N., Reaney M.J. and Hertz P.B. (2001), Preparation and characterization of bio-diesels from various bio-oils, Bioresour. Technol., 80: 53-62.

[4] Kumar A., Bhattacharya S.C. and Pham H.L. (2003), Greenhouse gas mitigation potential of biomass energy technologies in Vietnam using the long range energy alternative planning system model, Energy, 28 (7): 62754.

[5] Vicente Gemma, Martinez Mercedes and Aracil Jose (2004), Integrated biodiesel production: comparison of different homogeneous catalysts systems, Bioresour. Technol., 92: 297-305.

[6] Ramadhas A. S., Jayaraj S. and Muraleedharan C. (2005), Biodiesel production from high FFA rubber seed oil, Fuel, 84:. 335-340.

[7] Freedman B., Pryde E. H. and Mounts T.L. (1984), Variables affecting the yields of fatty esters from transesterified vegetable oils, JAOCS, 61(10): 16381643.

[8] Zullaikah Siti, Lai Chao-Chin, Vali Shaik Ramjan and Ju Yi-Hsu (2005), A two-step acid-catalyzed process for the production of biodiesel from rice bran oil Bioresour. Technol., 96: 1889-1896.

[9] Islam Md. Wahidul, Islam Mohammed Rafiquel, Khan Maksudur R., Islam M. A., Mozumder M. S. I., Siddiqee M N. and Rahman Mustafizur (2008), A threestep process for biodiesel production from vegetable oil, Proceedings of the international conference on chemical engineering, Dhaka, Bangladesh, jan 13-15, pp. 130134.

[10 ] Morshed Mahbub, Ferdous Kaniz, Khan Maksudur R., Mazumder M.S.I., Islam M.A. and Uddin Md. T. (2011), Rubber seed oil as a potential source for biodiesel production in Bangladesh, Fuel, 90:29812986.

[11] De B.K. and Bhattacharyya (1999), Biodiesel from minor vegetable oils like karanja oil and nahor oil, Wiley-VCH Verlag GmbH, D-69451 Weinheim, pp. 404-406.

[12] Official Methods and Recommended Practices of the American Oil Chemist's Society, 5th ed, AOCS Press, Champaign, 1998.

[13] Jeffery G. H., Bassett J., Mendham J. and Denney R. C. (1991), Vogel's Textbook of Quantitative Chemical Analysis, UK: Longman Scientific and Technical.

[14] Kanit Krisnangkura (1986), A Simple Method For Estimation of Cetane Index of Vegetable Oil Methyl Esters, JAOCS, 63: 552.

[15] Leung D.Y.C, Xuan Wu and Leung M.K.H (2010), A review on biodiesel production using catalyzed transesterification, Appl Energy, 87: 1083-1095.

[16] Joshi R.M. and Pegg M.J. (2007), Flow properties biodiesel fuel blends at low temperatures, Fuel, 86: 143 151. 